\title{
ASESMEN RESIKO BENCANA MENGGUNAKAN METODE KUALITATIF PADA KEL.PALL PUTIH DISTRIK SORONG BARAT
}

\section{Oleh :}

\author{
Jandri G Thenu, Ardiles Awola, Fifi S Macpal
}

\begin{abstract}
Abstrak
Bencana alam merupakan suatu ancaman yang dapat menimpa suatu kawasan dimanapun berada. Ini tentunya harus menjadi perhatian yang penting dalam rangka upaya pengurangan resiko bencana. kelurahan Pall Putih merupakan salah satu kelurahan yang berlokasi di Kota Sorong, tepatnya di Papua B a r a t Seperti yang diketahui, daerah Kota Sorong sering terjadi bencana seperti Banjir, Kekeringan, Gempa, Tanah longsor, dll. Pada penelitian ini mengasesmen resiko bencana tersebut. Metode yang digunakan adalah asesmen resiko bencana menggunakan metode kualitatif (Qualitative Risk Hazard Assessment). Parameter dan indikator penilaian yang digunakan mengacu pada British Columbia Provincial Emergency Program. Hasil dari penelitian menunjukkan bahwa resiko yang paling dominan pada daerah ini adalah bencana banjir.
\end{abstract}

Kata Kunci : Asesmen Resiko Bencana, Qualitative Risk Hazard Assessment, Kelurahan Pall Putih, Kota Sorong.

\section{Pendahuluan}

Kelurahan Pall Putih merupakan kelurahan yang terletak di Distrik Sorong Barat Kota Sorong Provinsi Papua Barat. Kelurahan Pall Putih merupakan salah satu kelurahan di Kota Sorong yang sering terkena dampak bencana banjir setiap musim hujan khususnya di Area Jalan Danau Toba, RT 002/ RW 002, RT 003/RW 002, RT 003/RW 003, RT 004/RW 003. Sehingga mengakibatkan kerusakan infrastruktur ( Jalan dan rumah-rumah penduduk ). Bencana lain pun terkadang sering terjadi seperti gempa bumi dan longsong dibeberapa titik yang dekat dengan perbukitan. Hal ini tentunya diperlukan suatu asesmen dalam rangka mengidentifikasi bencana mana yang memiliki resiko paling tinggi.

Pengurangan resiko ini sangat penting sebagai langkah mitigasi. Upaya mitigasi perlu dilakukan untuk mengidentifikasi bencana yang akan terjadi dikemudian hari dengan mengambil langkah antisipasi. Hal ini dilakukan dalam rangka untuk mengurangi resiko yang ditimbulkan sehingga tingkat kerugian dan korban yang berjatuhan dapat diminimalisir

Ada beberapa metode untuk melakukan asesmen resiko bencana yaitu metode kualitatif, metode kuantitatif dan metode semi-kuantitatif. Metode-metode tersebut memiliki berbagai keunggulan masing-masing. Metode kualitatif merupakan metode yang paling simpel digunakan dalam asesmen resiko terhadap bencana. Pada metode ini indikator dapat mengekspresikan tingkat resiko dari bencana tersebut seperti: sangat rendah, rendah, sedang, tinggi, atau sangat tinggi. Indikator ini bergantung pada standar acuan para ahli yang dipakai.

Standar acuan yang dipakai pada penelitian ini adalah mengacu pada British Columbia Provincial Emergency Program. Terdapat beberapa aspek yang diperhitungkan dalam acuan ini diantaranya adalah kematian (fatality), terluka (injured), fasilitas vital (critical facilities), fasilitas umum pendukung (life-lines), kerusakan harta milik (property damage), lingkungan (environment), dampak ekonomi dan sosial (economics and sosial impacts). Berdasarkan datadata tersebut maka dapat disajikan data dalam bentuk matrikulasi resiko/Risk Matrix. 


\section{Tujuan}

Penelitian ini bertujuan untuk melakukan langkah asesmen resiko bencana yang mungkin terjadi di Kelurahan Pall Putih Distrik Sorong Barat Kota Sorong, dengan mempertimbangkan beberapa bencana yang berpotensi pada daerah tersebut.

\section{Metode}

Metode yang digunakan pada penelitian ini mengikuti flowchart yang tersaji pada Gambar 1 di bawah ini.

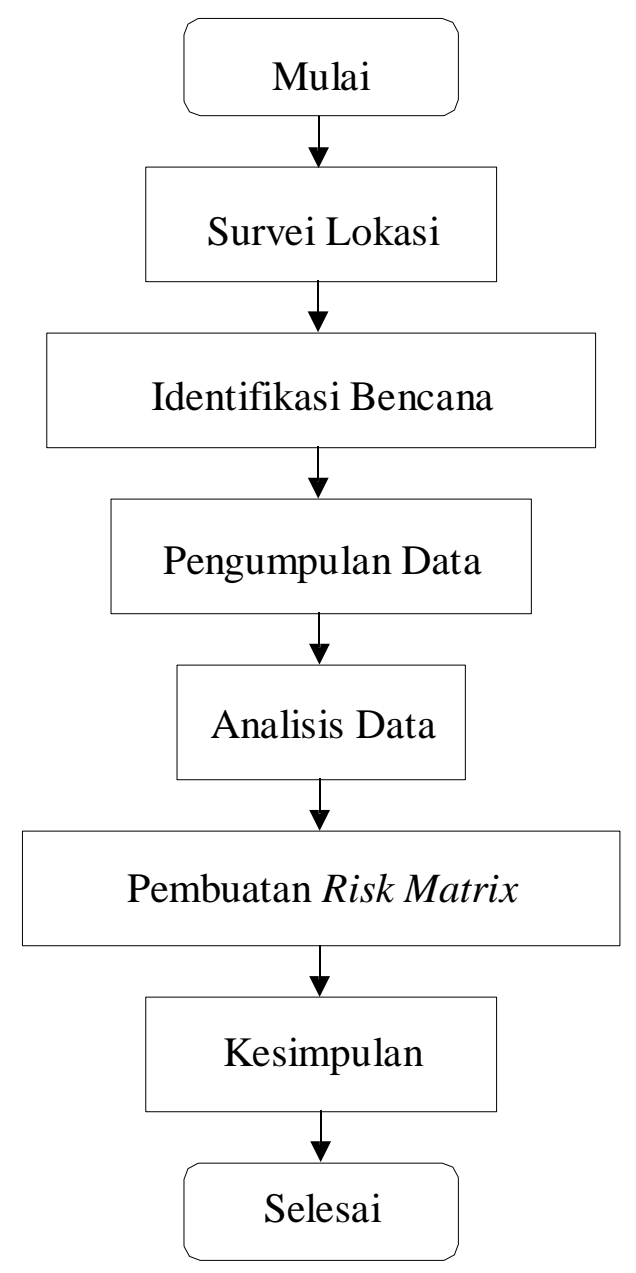

Gambar 1 Flowchart Metode Penelitian

Sumber : Saputro (2018) 


\section{Analisis dan Pembahasan}

\section{- Survei Lokasi dan Identifikasi bencana}

Penelitian dilakukan pada Jalan Danau Maninjau, Kelurahan Pall Putih Distrik Sorong Barat Kota Sorong. Daerah ini memiliki luas sekitar 0,5 Ha. Survei lokasi dilakukan untuk mengetahui kondisi tempat penelitian secara langsung. Selain itu, terdapat beberapa data sekunder yang diperlukan sebagai bahan pertimbangan dalam melakukan proses analisis. Data sekunder yang diperlukan

seperti data penduduk. Adapun tempat lokasi penelitian tersaji pada Gambar 2 berikut ini

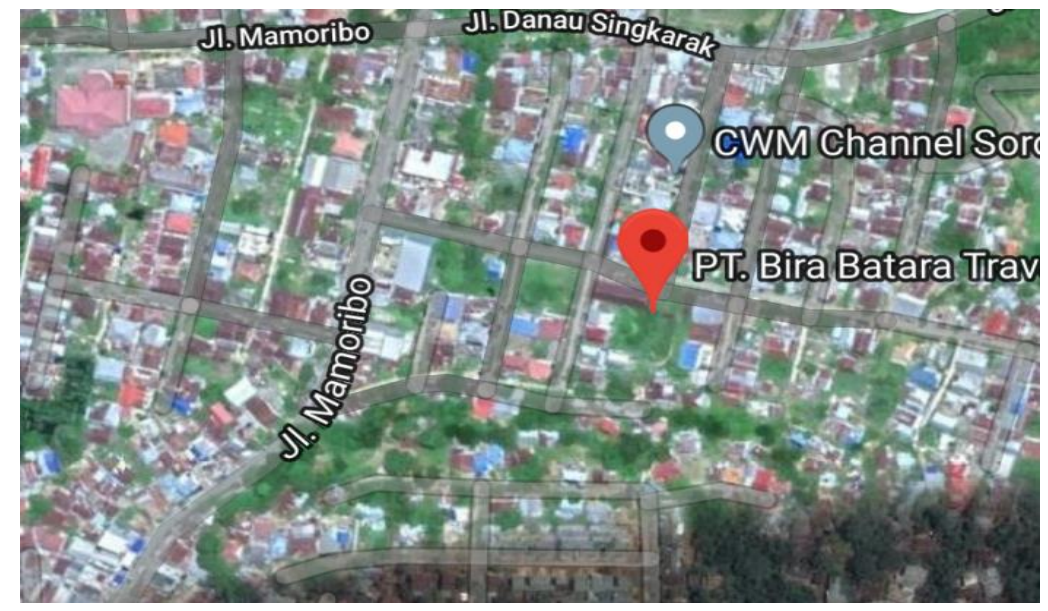

Gambar 2 Lokasi Penelitian (Google Map, 2018)

\section{- Pengumpulan Data}

Pengumpulan data terkait penelitian terhadap daerah Jalan Danau Maninjau Kelurahan Pall Putih, dilakukan dengan mendatangi kantor kelurahan untuk mengetahui jumlah penduduk dan penyebarannya menurut usia, dan tingkat pendidikan masyarakat sekitar. Setelah itu, melakukan wawancara langsung terhadap perangkat desa setempat. Kantor Kelurahan Pall Putih terlihat pada Gambar 3 berikut.

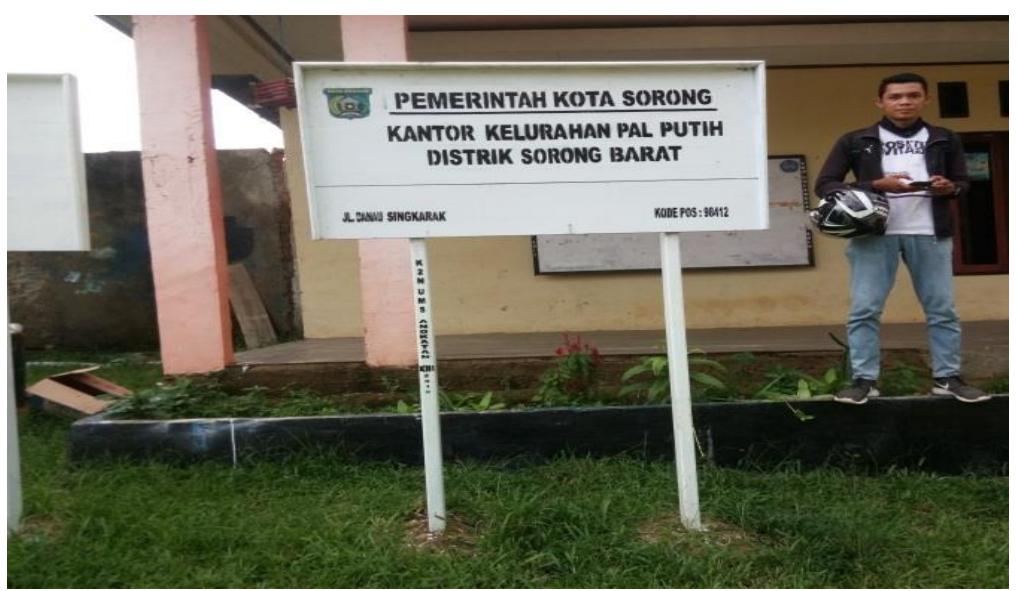

Gambar 3. Kantor Kelurahan Pall Putih 
Dari hasil survei yang dilakukan pada RT 002/ RW 002, RT 003/RW 002, RT 003/RW 003, RT 004/RW 003 Jalan Danau Maninjau Kelurahan Pall Putih maka diperoleh beberapa data yaitu jumlah penduduk berdasarkan jenis kelamin pada Tabel 1, jumlah penduduk menurut pendidikan pada Tabel 2, jumlah penduduk menurut pekerjaan Tabel 3 dan Penyebaran penduduk tahun

2018 pada Tabel 4.

Tabel 1 . Jumlah Penduduk Berdasarkan Jenis Kelamin

\begin{tabular}{|c|l|c|c|c|c|}
\hline \multirow{2}{*}{ No } & \multirow{2}{*}{ RT/ RW } & \multicolumn{2}{|c|}{ Jenis Kelamin } & \multirow{2}{*}{$\begin{array}{c}\text { Jumlah } \\
\text { Total }\end{array}$} & $\begin{array}{c}\text { Jumlah } \\
\text { KK }\end{array}$ \\
\cline { 3 - 4 } 1 & RT 02 /02 & 290 & 312 & 602 & 165 \\
2 & RT 02 /03 & 277 & 271 & 548 & 149 \\
3 & RT 03 /03 & 342 & 375 & 717 & 201 \\
\multirow{2}{*}{4} & RT 04 /04 & 399 & 408 & 807 & 288 \\
\hline \multicolumn{2}{|c|}{ JUMLAH } & $\mathbf{1 3 0 8}$ & $\mathbf{1 3 6 6}$ & $\mathbf{2 6 7 4}$ & $\mathbf{8 0 3}$ \\
\hline
\end{tabular}

Sumber : Data Administrasi Kelurahan Pall Putih Distrik Sorong Barat

Tabel 2 . Jumlah Penduduk Menurut Pendidikan

\begin{tabular}{|c|c|}
\hline Pendidikan Terakhir & Jumlah \\
\hline TK & 278 \\
SEKOLAH DASAR & 369 \\
SLTP & 455 \\
SLTA & 567 \\
AKADEMI/D3 & 301 \\
SARJANA & 478 \\
\hline
\end{tabular}

Sumber : Data Kantor Kelurahan Pall Putih Distrik Sorong Barat 
Tabel 3 . Jumlah Penduduk Menurut Pekerjaan

\begin{tabular}{|c|c|}
\hline Pendidikan Terakhir & Jumlah \\
\hline PNS & 99 \\
PEGAWAI SWASTA & 332 \\
ABRI & 32 \\
PERTUKANGAN & 170 \\
JASA & 550 \\
WIRASWASTA/ PEDAGANG & 340 \\
TANI & 8 \\
PENSIUNAN & 188 \\
LAIN-LAIN & 55 \\
\hline
\end{tabular}

Sumber : Data Kantor Kelurahan Pall Putih Distrik Sorong Barat

Tabel 4 . Penyebaran Penduduk RT Kelurahan Pall Putih Tahun 2018

\begin{tabular}{|c|c|c|c|c|c|c|}
\hline No & $\begin{array}{c}\text { Struktur } \\
\text { Umur }\end{array}$ & $\begin{array}{c}\text { RT 02 } \\
/ \mathbf{0 2}\end{array}$ & $\begin{array}{c}\text { RT 02 } \\
\mathbf{/ 0 3}\end{array}$ & $\begin{array}{c}\text { RT 03 } \\
/ \mathbf{0 3}\end{array}$ & $\begin{array}{c}\text { RT 04 } \\
\text { /04 }\end{array}$ & Jumlah \\
\hline 1 & $0-14$ & 77 & 76 & 60 & 81 & 294 \\
2 & $15-24$ & 132 & 267 & 154 & 281 & 834 \\
3 & $25-49$ & 286 & 301 & 249 & 255 & 1091 \\
4 & $>50$ & 132 & 99 & 122 & 102 & 455 \\
\hline \multicolumn{2}{|r|}{ Jumlah Total } & $\mathbf{6 2 7}$ & $\mathbf{7 4 3}$ & $\mathbf{5 8 5}$ & $\mathbf{7 1 9}$ & $\mathbf{2 6 7 4}$ \\
\hline
\end{tabular}

Sumber : Pemetaan Swadaya Kelurahan Pall Putih 2018

Dari data-data diatas kemudian dilakukan penentuan parameter dan indikator yang akan digunakan untuk melakukan penilaian.

\section{Indikator Penilaian British Columbia Provincial Emergency Program}

Pada penelitian ini menggunakan indikator penilaian yang mengacu pada British Columbia Provincial Emergency Program yang memuat beberapa aspek seperti kematian (fatality), terluka (injured), fasilitas vital (critical facilities), fasilitas umum pendukung (lifelines), kerusakan harta milik (property damage), lingkungan (environment), dampak ekonomi dan sosial (economics and sosial impacts). Untuk penjelasan mengenai kriterianya tersaji pada Tabel 6 sampai Tabel 12. Adapun Tabel 5 menjelaskan kriteria tentang kemungkinan bencana tersebut terjadi. 
Tabel 5 Kemungkinan Bahaya

\begin{tabular}{ccc}
\hline Skala & Keterangan & Kriteria \\
\hline 1 & Sangat tidak mungkin & $0 \%$ to $5 \%$ \\
2 & Tidak mungkin & $6 \%$ to $15 \%$ \\
3 & Sedang & $16 \%$ to $60 \%$ \\
4 & Mungkin & $61 \%$ to $60 \%$ \\
5 & Sangat mungkin & $>90 \%$ \\
\hline
\end{tabular}

Tabel 6 Korban Meninggal

\begin{tabular}{ccc}
\hline Skala & Keterangan & Kriteria \\
\hline 1 & Sangat Rendah & $0-4$ \\
2 & Rendah & $4-10$ \\
3 & Tinggi & $10-50$ \\
4 & Sangat Tinggi & $>50$ \\
\hline
\end{tabular}

Tabel 7 Korban Luka-luka

\begin{tabular}{ccc}
\hline Skala & Keterangan & Kriteria \\
\hline 1 & Sangat Rendah & $0-4$ \\
2 & Rendah & $4-50$ \\
3 & Tinggi & $50-2000$ \\
4 & Sangat Tinggi & $>2000$ \\
\hline
\end{tabular}

Tabel 8 Fasilitas Vital Kritis

\begin{tabular}{ccc}
\hline Skala & Keterangan & Kriteria \\
\hline 1 & Sangat Rendah & Relokasi sementara \\
2 & Rendah & Tutup dalam beberapa hari \\
3 & Tinggi & Kehilangan kemampuan hingga lebih $50 \%$ \\
4 & Sangat Tinggi & Pulih dalam waktu lama \\
\hline
\end{tabular}

Tabel 9 Fasilitas Umum Pendukung

\begin{tabular}{ccc}
\hline Skala & Keterangan & Kriteria \\
\hline 1 & Sangat Rendah & Terganggu sementara \\
2 & Rendah & Terganggu selama beberapa hari \\
3 & Tinggi & Terganggu selama 1 minggu \\
4 & Sangat Tinggi & Tidak berfungsi dalam waktu lama \\
\hline
\end{tabular}

Tabel 10 Kerusakan Harta Milik

\begin{tabular}{|c|c|c|}
\hline Skala & Keterangan & Kriteria \\
\hline 1 & Sangat Rendah & Kerusakan minimal \\
\hline 2 & Rendah & Kerusakan ringan dan cakupan area lokal \\
\hline 3 & Tinggi & Kerusakan berat dan cakupan area lokal \\
\hline 4 & Sangat Tinggi & Kerusakan berat dan cakupan area luas \\
\hline
\end{tabular}


Tabel 11 Lingkungan

\begin{tabular}{ccc}
\hline Skala & Keterangan & Kriteria \\
\hline 1 & Sangat Rendah & Kerusakan minimal \\
2 & Rendah & Kerusakan ringan dan cakupan area lokal \\
3 & Tinggi & Kerusakan berat dan cakupan area lokal \\
4 & Sangat Tinggi & Kerusakan berat dan cakupan area luas \\
\hline
\end{tabular}

Tabel 12 Sosial dan Ekonomi

\begin{tabular}{ccc}
\hline Skala & Keterangan & Kriteria \\
\hline 1 & Sangat Rendah & Berdampak Sementara pada cakupan area lokal \\
2 & Rendah & Berdampak Sementara pada cakupan area luas \\
3 & Tinggi & Berdampak lama pada cakupan area luas \\
4 & Sangat Tinggi & Gangguan berdampak lama \\
\hline
\end{tabular}

Jenis bencana yang akan diperhitungkan pada asesmen ini adalah Banjir, longsor dan gempa bumi. Asesmen pada bencana tersebut dinilai dengan menggunakan motede Qualitative Risk Hazard Assessment.

Setelah menentukan parameter dan nilai yang akan digunakan kemudian langsung mengevaluasi lokasi kelurahan. Berdasarkan hasil survey pengumpulan data wawancara terhadap perangkat kelurahan setempat, maka data dapat disajikan seperti pada Tabel berikut:

Tabel 13. Hasil Pengumpulan Data

\begin{tabular}{|c|c|c|c|c|}
\hline \multirow{2}{*}{ Bencana } & \multirow{2}{*}{$\begin{array}{c}\text { Probabilitas } \\
\text { Kejadian }\end{array}$} & \multicolumn{3}{|c|}{ Dampak/ Konsekuensi } \\
\cline { 3 - 5 } & Kematian & $\begin{array}{c}\text { Luka- } \\
\text { Luka }\end{array}$ & Dampak Ke Fasilitas \\
\hline Banjir & $61 \%$ to $60 \%$ & 0 & 0 & $\begin{array}{c}\text { Kerusakan Jalan dan } \\
\text { Bangunan Rumah }\end{array}$ \\
\hline Longsor & $16 \%$ to $60 \%$ & 0 & 0 & - \\
\hline Gempa Bumi & $6 \%$ to $15 \%$ & 0 & 0 & - \\
\hline
\end{tabular}

Tabel 14. Hasil Pengumpulan Data

\begin{tabular}{|c|c|c|}
\hline \multirow{2}{*}{ Bencana } & \multicolumn{2}{|c|}{ Dampak/ Konsekuensi } \\
\cline { 2 - 3 } & Fasilitas UmumPendukung & Kerusakan Properti \\
\hline Banjir & Terganggu Sementara & Rumah dan Kantor \\
\hline Longsor & Terganggu Seminggu & Rumah \\
\hline Gempa Bumi & - & - \\
\hline
\end{tabular}


Tabel 15. Hasil Pengumpulan Data

\begin{tabular}{|c|c|c|}
\hline \multirow{2}{*}{ Hazard } & \multicolumn{2}{|c|}{ Dampak/ Konsekuensi } \\
\cline { 2 - 3 } & Lingkungan & Sosial dan Ekonomi \\
\hline Banjir & Kerusakan Minimal & Gangguan Berdampak Lama \\
\hline Longsor & $\begin{array}{c}\text { Kerusakan Minimal dan } \\
\text { Cakupan Area Lokasi }\end{array}$ & Berdampak Sementara \\
\hline Gempa Bumi & Kerusakan Minimal & Berdampak Sementara \\
\hline
\end{tabular}

Tabel 16 Penilaian dampak/konsekuensi

\begin{tabular}{|c|c|c|c|c|c|c|c|c|}
\hline Bencana & $\begin{array}{c}\text { Kemungkinan } \\
\text { Terjadi }\end{array}$ & Meninggal & Luka-luka & $\begin{array}{c}\text { Fasilitas } \\
\text { Vital }\end{array}$ & $\begin{array}{c}\text { Fasilitas } \\
\text { Umum }\end{array}$ & $\begin{array}{c}\text { Kerusakan } \\
\text { Harta }\end{array}$ & $\begin{array}{c}\text { Sosial } \\
\text { dan } \\
\text { Ekonom }\end{array}$ & Jumlah \\
\hline Banjir & 4 & 1 & 1 & 1 & 1 & 1 & 3 & 12 \\
\hline Longsor & 3 & 1 & 1 & 1 & 3 & 1 & 1 & 11 \\
\hline Gempa Bumi & 2 & 1 & 1 & 1 & 1 & 1 & 1 & 8 \\
\hline
\end{tabular}

Tabel 16 menunjukkan hasil rekapitulasi dari asesmen terhadap bencana mungkin terjadi di daerah Kelurahan Pall Putih. Hasil skor penilaian dampak terbesar adalah pada bencana Banjir yaitu sebanyak 12 poin. Hal ini tentunya wajar mengingat di daerah Pall Putih kondisi drainase sangat buruk. Setelah itu potensi bencana yang besar berikutnya adalah longsor karena ada beberapa daerah perbukitan. Nilai-nilai tersebut kemudian dibuat dalam suatu matrikulasi resiko/risk matrix. Matrikulasi Resiko bencana pada kelurahan Pall Putih tersaji pada Gambar 4 berikut.

\begin{tabular}{|c|c|c|c|c|c|c|}
\hline & \multirow{2}{*}{ Kemungkinan Terjadi } & \multicolumn{5}{|c|}{ Tingkat Dampak } \\
\hline & & Minimal & Sedikit & Sedang & Parah & Sangat Parah \\
\hline 5 & Sangat Mungkin & & & & & \\
\hline 4 & Mungkin & & & BANIIR & & \\
\hline 3 & Sedang & & LONGSOR & & & \\
\hline 2 & Tidak Mungkin & & $\begin{array}{l}\text { GEMPA } \\
\text { BUMI }\end{array}$ & & & \\
\hline 1 & Sangat Tidak Mungkin & & & & & \\
\hline & Skala Dampak & Sangat Rendah & Rendah & Sedang & Tinggi & Sangat Tinggi \\
\hline & Skor & $1-6$ & $7-12$ & $13-18$ & $19-23$ & $24-28$ \\
\hline
\end{tabular}




\section{Kesimpulan}

Dari hasil asesmen resiko (risk assessment) dengan menggunakan metode qualitative risk hazard assessment diperoleh hasil bahwa pada Kelurahan pall Putih, bencana/hazard yang paling dominan atau terparah itu adalah Banjir. Salah satu penyebabnya Kondisi Drainase yang tidak baik dan sebagian besar tidak ada saluran drainase. Sehingga menyebabkan kerusakan terhadap rumah warga maupun fasilitas pemerintahan.

Hal ini dapat disimpulkan bahwa kerentanan terhadap anak-anak dan orang lanjut usia sangat tinggi. Sehingga perlu dilakukan sosialisasi bagaimana upaya penyelamatan apabila terjadi banjir. 


\section{Daftar Pustaka}

Columbia, British (2004). Hazard, Risk, and Vurnerability Analysis Tool Kit. Provincial Emergency Program.

Saputro, I. T. (2018). Analisis Perbandingan Kurva Hazard Pada Kota Banda Aceh Dengan Sumber Gempa Sesar Seulimeum Dan Menggunakan Beberapa Fungsi Atenuasi.

Saputro, I. T. (2018). ASESMEN RESIKO BENCANA MENGGUNAKAN METODE KUALITATIF PADA DESA IMOGIRI.

Widodo (2013). Natural Hazard Risk Assessment. Bahan Kuliah. Universitas Islam Indonesia. Yogyakarta

https://www.google.com/map 